\title{
A pesquisa sobre o fazer pesquisa: uma análise de citação da literatura periódica em Ciência da Informação
}

Juliana Lazzarotto Freitas, Leilah Santiago Bufrem, Ely Francina Tannuri de Oliveira, Maria Cláudia Cabrini Grácio

\begin{abstract}
Resumo
Introdução: Considera que a literatura na área de Ciência da Informação (Cl) compreende uma diversidade temática com baixo destaque para assuntos relacionados aos modos de fazer pesquisa. Analisa a produção científica dos autores que tratam da temática metodologia de pesquisa na literatura de Ciência da Informação $(\mathrm{Cl})$ e o referencial no qual se fundamentam as questões metodológicas relativas à área. Discute as posições metodológicas e epistemológicas dos pesquisadores destacados como mais produtivos nacionalmente na temática. Método: Adota a modalidade de análise de conteúdo aliada aos estudos métricos para contextualizar os indicadores gerados referentes à produção, à colaboração relacionada aos tipos de autoria e à análise de citação. Considera o acoplamento bibliográfico como uma modalidade de análise em que são estudadas as citações concomitantes. Desenvolve referencial teórico sobre a importância da análise de produção científica nos domínios do conhecimento. Explora concepções teóricas sobre metodologia de pesquisa e a complementaridade desta com a epistemologia no fazer pesquisa. Resultados: Evidencia, na produção dos autores, a metodologia como foco temático aplicado a contextos da $\mathrm{Cl}$ e também como objeto de pesquisa da referida área. Considera que a produtividade proeminente dos autores justifica-se especialmente pelo aprofundamento nos metaestudos sobre modos de fazer pesquisa em $\mathrm{Cl}$. Identifica a tendência aos estudos de autoria única sobre o tema. Conclusões: Considera que a realização de metaestudos e também de estudos aplicados e metodológicos é importante para que se reconheça, na área de $\mathrm{Cl}$, um núcleo teórico e prático consistente. Em relação às influências epistemológicas identificadas com a análise de acoplamento, observa que a epistemologia racionalista crítica e a epistemologia social e política são destacadas na construção do referencial teórico dos autores.
\end{abstract}

\section{Palavras-chave}

Ciência da Informação. Análise da produção científica. Análise de citação. Acoplamento bibliográfico. Metodologia da pesquisa.

\section{Introdução}

A literatura na área de Ciência da Informação (CI) compreende uma diversidade temática com baixo destaque para assuntos relacionados aos modos de fazer pesquisa. Valoriza-se, neste estudo, a importância de se reverem procedimentos alternativos de pesquisa, partindo-se do pressuposto que a identificação de estudos relativos a essas modalidades na área de CI é uma tentativa de contribuição em relação ao seu domínio científico. Trata-se de uma aproximação com seus fundamentos teóricos, epistemológicos e a visualização das inquietações dos pesquisadores.
A temática eleita decorreu da intenção de que se esclareçam as relações de um domínio de pesquisa científica com os métodos construídos pelos estudiosos em suas práticas de pesquisa, entendendo-se como domínio um "produto da história da metodologia, da teoria e da descoberta científicas ao longo de muitos séculos". Mesmo que em estado maduro, os domínios estão, segundo Lloyd, "em constante processo de refinamento" (LLOYD, 1995, p. 38, 39). Com base nessa premissa, pode-se afirmar a necessidade de autoconhecimento dos domínios da ciência, de espaços de questionamento sobre como os autores tratam as questões relativas à metodologia de pesquisa 
na literatura científica e sobre os quadros teóricos em que se fundamentam.

A realização de uma pesquisa sobre pesquisa tem sido denominada de metaestudo, ou seja, um voltar-se da pesquisa para si mesma, como meio para que a ciência produzida se reconheça e os membros da comunidade científica conheçam as pesquisas que vêm sendo desenvolvidas em sua área.

Assim, identificam-se os autores que tratam da temática metodologia de pesquisa na literatura científica de CI e em qual referencial estes autores se fundamentam para emergir suas preocupações metodológicas relativas a esse campo do conhecimento.

Considera-se, para a realização desse intento, a combinação de diferentes modalidades métricas, em especial com indicadores de produção e de citação, abarcando nesta última modalidade o acoplamento bibliográfico, pela qual se relacionam as citações concomitantes. A opção metodológica pela análise de citação remete às características estruturantes que compõem o cenário das pesquisas científicas, representando assim o processo dinâmico, social e histórico das relações existentes em um domínio científico, relações que podem ser de diferentes naturezas: temáticas, institucionais, entre autores seminais e aqueles por eles influenciados, entre outras. Busca-se ampliar e consolidar o entendimento sobre as posições metodológicas dos pesquisadores mais representativos nacionalmente nesta temática e seus respectivos fundamentos teóricos.

\section{Fundamento teórico-metodológico da investigação}

O estudo e o resgate histórico da produção científica de uma área, considerando suas estruturas teórico-metodológicas, favorecem, segundo Lloyd, a compreensão de um domínio científico (1995, p. 38). Para o autor, "a análise de uma construção científica permite melhor compreender as explicações e o emprego de arcabouços que incluem pressupostos metodológicos e filosóficos".
Em relação à modalidade de análise de citação, para Grácio e Oliveira (2013a), o fundamento das citações é a consideração de que um artigo científico, por menor que seja sua contribuição científica, faz avançar o conhecimento na área. Entretanto, um artigo não é uma entidade solitária, mas está imerso na literatura sobre o tema, de modo que a obra de um autor se constrói sobre a produção daqueles que o precederam. Como elementos indicadores dessa literatura, as citações são indícios de tendências e posturas teóricas, metodológicas e consequentemente epistemológicas.

O conjunto de citações de uma pesquisa permite a identificação de autores cujas teorias, conceitos ou métodos serviram de base no desenvolvimento de uma pesquisa, como argumentam Vanz e Caregnato (2003). Assim, criam-se novos conhecimentos a partir da relação entre as citações e as expectativas dos pesquisadores.

Segundo Meadows (1999), uma forma de avaliar a qualidade de uma produção consiste em verificar o nível de interesse que ela provoca. Isso pode ser medido por meio da quantidade de citações nas referências bibliográficas em momento posterior. Essa evidência quantitativa também pode se manifestar em relação ao acoplamento.

O acoplamento bibliográfico analisa as semelhanças entre dois artigos ou autores comparando as referências comuns aos dois (GLÄNZEL, 2003; GUEDES; BORSCHIVER, 2005; LUCAS; GARCIA-ZORITA, 2014). Complementando o exposto, pondera-se também o fato de que a pesquisa científica e a geração de conhecimento em determinada área pode ser aprimorada com a reflexão sobre os modos de fazer pesquisa e as epistemologias que os fundam (SÁNCHEZ-GAMBOA, 1997, p. 67).

Os estudos sobre opções metodológicas vêm ao encontro destas preocupações, quando se considera que a metodologia é essencial na construção do conhecimento científico. Entretanto, deve-se reconhecer também que toda metodologia integra-se a uma epistemologia (RENDÓN ROJAS, 2008, p. 5). Portanto, o rigor e as exigências da 
prática metodológica decorrem dos pressupostos epistemológicos que fundamentam as pesquisas. Essa posição se evidencia nos argumentos de González de Gómez (2000, p. 1), ao afirmar que:

Os métodos, quantitativos, qualitativos, comparativos, assim como as técnicas de coleta e análise da informação, definem a direção e modalidade das ações de pesquisa de modo secundário, estando já ancorados num domínio epistemológico e político que acolhe e legitima as condições de produção do objeto da pesquisa.

A concepção da autora em relação às opções metodológicas eleitas na produção científica por seus autores considera a complexidade da pesquisa científica como um processo informacional, em que permeiam posições ideológicas e políticas. Tais posições podem ser identificadas a partir do estudo dos métodos e das epistemologias que os fundam. Nesse sentido, Bufrem (2009a, p. 5) defende que

a produção científica, seja qualquer o seu grau de desenvolvimento ou a sua formalização metodológica, sempre pressupõe formas de consciência, pelas quais os pesquisadores dão sentido e significado às suas práticas.

Adota-se para o presente trabalho a concepção de metodologia como

[...] o domínio que dá suporte teórico, estrutural, técnico e epistemológico à apreensão, análise, compreensão e/ou explicação de objetos suscetíveis à investigação, buscando primeiramente auxiliar o pesquisador na definição do tema e em como torná-lo relevante ao desenvolvimento de um campo científico, a fim de contribuir com o processo de conscientização e crítica (FREITAS, 2012, p. 23).

Evidencia-se que a metodologia de pesquisa, ou seja, os modos de fazer pesquisa contemplam dimensões diferenciadas que se integram em um modelo quadripolar da prática metodológica, proposto por Bruyne, Herman e Schoutheete (1977). Essas dimensões complementares são denominadas pelos autores como polos epistemológico, morfológico, teórico e técnico. Bufrem (2013) complementa esse olhar em relação ao fazer científico com as dimensões política e ética que integram as relações existentes em um domínio científico.
Nesse mesmo encaminhamento, Chalmers (2000, p. 188) não considera aceitável que uma metodologia determine a adoção ou preferência por uma teoria em detrimento de outra em uma dada situação, ou "adotar teorias que tenham maior apoio indutivo pelos seus feitos aceitos". O fato de algumas teorias serem incompatíveis com os "feitos geralmente aceitos e com os episódios da ciência comumente considerados como constitutivos de suas fases mais progressivas" confirma a condição dominante do ensino e da aplicação da metodologia na ciência como "provedora de regra para guias científicos”. Dessa condição decorre o desuso de outras teorias e métodos assim como a continuidade e reprodução de modelos teóricos e instrumentais. (CHALMERS, 2000, p. 188).

As concepções presentes neste estudo permitem a ampliação da consciência sobre o que se vem realizando em termos práticos de pesquisa e buscam favorecer a superação da adoção acrítica de modos de pesquisa já reconhecidos, permitindo a criação de condições mais favoráveis à investigação científica.

\section{Trajetória metodológica do estudo}

A trajetória metodológica deste estudo sustentou-se nas análises de conteúdo e de citação como suporte para a pesquisa. O corpus de artigos sobre o tema foi extraído da Base Referencial de Artigos de Periódicos em Ciência da Informação (Brapci), correspondendo ao período de 1970 a 2012. Os 26 artigos, assinados por 43 autores (em autoria ou coautoria) constituíram o corpus de análise. Este corpus é resultado da pesquisa intitulada $O$ ensino da metodologia científica: repercussões na produção científica em Ciência da Informação (FREITAS; BUFREM, 2013) voltada, entre outros objetivos, para uma categorização temática dos artigos da área de CI. Neste, a busca na Brapci foi feita pelos termos "metodologia" e "pesquisa" para abranger as variações: metodologia da pesquisa, metodologia de pesquisa e também uma busca por "metodologia científica" e "método científico". As três buscas foram feitas pelos campos: título, palavra-chave e resumo. 
Foram identificados os autores mais produtivos na temática, os tipos de autoria e colaboração científica. Para a realização da análise de citação e de acoplamento, as referências utilizadas pelos quatro autores mais representativos da temática foram sistematizadas no software Excel, identificando-se, desse modo, os autores mais citados por eles. Em seguida, criou-se uma matriz para a geração de gráfico no software Ucinet, no qual são representados os autores mais citados pelos autores mais produtivos, assim como os autores por eles acoplados. Isso foi possível porque o corpus de autores foi pouco expressivo numericamente. Assim, a partir das citações puderam ser destacados os posicionamentos representantes da frente de pesquisa nacional sobre o tema, assim como seus referenciais.

\section{Resultados}

Os resultados desdobram-se nos seguintes itens: autores mais representativos na temática selecionada para a pesquisa, tipos de autoria encontrados no corpus de análise, análise de conteúdo dos artigos dos autores mais representativos e análise de citação destes, por meio de acoplamento bibliográfico.

\section{Análise de conteúdo das pesquisas dos autores mais representativos}

Em virtude da produção quantitativamente pouco expressiva sobre o tema, elencaram-se somente as quatro autoras mais representadas no corpus dos 26 artigos recuperados, cada uma com duas publicações, a saber: Gilda Olinto do Valle Silva, Leilah Santiago Bufrem, Maria Nélida González de Gómez e Maria Yêda F. S. de Filgueiras Gomes, responsáveis por $30,76 \%$ do corpus.

Busca-se aqui, retratar as relações mais evidentes nas pesquisas da área, por meio da análise dos autores que citam e de suas vertentes metodológicas e teóricas nos estudos analisados.

Na produção científica identificada, observa-se a metodologia como foco temático aplicado a con-
Tabela - Autoras mais representativas do corpus

\begin{tabular}{lcc}
\hline Nome do autor & Instituição & Total Trab. \\
\hline BUFREM, L. S. & UFPR & 2 \\
GOMES, M. Y. F. S. de F. & UFBA & 2 \\
GONZÁLEZ DE GÓMEZ, M. N. & UFF & 2 \\
SILVA, G. O. do V. & IBICT & 2 \\
\hline
\end{tabular}

Fonte: os autores, 2014.

textos da CI e também como objeto de pesquisa da referida área.

A destacada produtividade dessas autoras justifica-se pelo aprofundamento nos metaestudos sobre modos de fazer pesquisa na área, na pesquisa sobre modelos conceituais no âmbito da organização e gestão da informação e do conhecimento e em relação aos modelos de ensino e aprendizagem dos cursos de Biblioteconomia e Ciência da Informação.

$\mathrm{Na}$ análise de conteúdo dos artigos a autora González de Gómez, com dois artigos teóricos sobre o tema, apresenta a metodologia como objeto de pesquisa, e a expressão de um pensamento cujo esforço e intenção voltam-se à produção do conhecimento numa perspectiva histórica, social, política e epistemológica já definida. De acordo com a autora, se as estratégias metodológicas são definidas em horizontes concretos de possibilidades políticas e epistemológicas, os programas de pesquisa em Ciência da Informação, vinculados às Ciências Sociais, são duplamente afetados, em sua estrutura paradigmática e em seus conteúdos teóricos e empíricos, pela configuração social dos regimes de informação (GONZÁLEZ DE GÓMEZ, 2000). Afirma que o escopo e a abrangência de um programa de pesquisa definem-se em três espaços gnosiológicos com diferentes demandas e culturas que direcionam a perspectiva de uma sociedade da informação: o da comunidade de pesquisa, o de gestão e avaliação da ciência e o da rede ampla de pares.

Silva (1987), em um de seus artigos, representa um modelo conceitual para consolidar um programa de metodologia de pesquisa que visa o maior rigor e eficiência no processo da pesquisa para a área. O modelo consiste primeiramente 
na elaboração de uma matriz de dados com as variáveis e casos a serem estudados, na segunda etapa propõe um trabalho de campo para preencher essa matriz de dados e na terceira, a matriz é analisada. Percebe-se que a autora denota uma preocupação com o modo adequado de se elaborar uma pesquisa, desde a delimitação do problema científico às variáveis que o permeiam. Em seu segundo artigo, Silva (1990) apresenta vários aspectos e etapas que podem ser considerados em um trabalho sobre um único conceito, isto é, mostra como esse conceito pode ser trabalhado teórica e empiricamente em uma única pesquisa. Como exemplo, utiliza o conceito de "uso de biblioteca" aplicado em uma pesquisa feita com alunos de uma escola de $2^{\circ}$ grau no Rio de Janeiro. Observa-se que a autora busca em seu referencial, aporte na epistemologia crítica de Karl Popper, a qual será clarificada no decorrer do estudo, por meio dos acoplamentos, considerando que Popper também está presente no referencial de Bufrem e Santos (2009b).

Bufrem, Costa, Gabriel Júnior e Pinto (2010) realizam um estudo metodológico que foi operacionalizado e validado na mesma pesquisa. Estes propõem uma metodologia para a criação de ambiente integrado de monitoramento e gerenciamento de publicações periódicas para composição de dados da Base de Dados Referencial de Artigos de Periódicos em Ciência da Informação (Brapci). Os autores definem e analisam variáveis orientadoras da pesquisa e, por meio de um estudo exploratório e mapeamento das demandas dos usuários, realizam a testagem de um protótipo para a concretização da proposta. Descrevem o planejamento, construção, implementação e validação do produto funcional do sistema, utilizando a rede internet como plataforma de aplicação. Já no segundo artigo, Bufrem e Santos (2009b) elaboram um estudo de enfoque prioritariamente teórico a fim de analisar a aplicabilidade e o uso da etnografia como metodologia para explorar a pesquisa na área da CI. Essa pesquisa visou destacar, na produção científica da área, a etnografia como método de construção científica, a partir de reflexões sobre sua aplicação no reconhecimento de valores subjetivos, permitindo um olhar crítico sobre a pesquisa no campo da CI. As autoras reconhecem no estudo, o valor do método etnográfico, oriundo da antropologia, para a apreensão e análise de um contexto multicultural, entendendo a cultura da informação sob uma perspectiva emergente na área em estudo, cujo aprofundamento requer valores e instrumentos antropológicos coerentes com as diversas áreas interdisciplinares que compõem o campo científico da informação. Por meio da análise interpretativa do discurso de diversos autores, as autoras buscam a reflexão que priorize a representação qualitativa do conhecimento.

Nota-se uma preocupação com a valorização e explicitação da informação social e culturalmente construída, como produto e objeto de estudo na área da CI.

Observa-se que Bufrem e seus coautores em ambos os estudos (2009b; 2010), sob uma ótica filosófica da informação e da pesquisa como sistema dinâmico de construção que tem dimensões éticas e políticas, concebem a metodologia de pesquisa como um conjunto de atividades que auxilia a compreensão do próprio processo de investigação e não somente visa o produto final da pesquisa.

Gomes (2006), também voltada ao valor da análise da produção científica para o desenvolvimento da ciência, analisa as dissertações defendidas no Programa de Pós-Graduação em Ciência da Informação da Universidade Federal de Minas Gerais (UFMG) em um período de dez anos. A autora identifica as tendências temáticas, os tipos de pesquisa e as abordagens metodológicas predominantes nas dissertações, constatando como predominantes: gerência de serviços e unidades de informação; estudos de usuário, demanda e uso da informação e de unidades de informação e comunicação, divulgação e produção editorial. Constata também a presença marcante da pesquisa empírica e o predomínio dos estudos baseados em dados quantitativos. Evidencia que o estudo de caso foi a metodologia mais utilizada, com $50 \%$ do total das dissertações, enquanto a pesquisa teórica esteve presente em apenas três dissertações, $5 \%$ do total analisado. Gomes, ainda em 2006, no artigo intitulado "Tendências atuais 
da produção científica em Biblioteconomia e Ciência da Informação no Brasil" constata o reduzido número de trabalhos cujo objeto de análise é o conhecimento produzido na área. Apesar de pouco numerosos, os resultados desses estudos constituem indicadores das tendências da pesquisa em Biblioteconomia e Ciência da Informação, além de apontarem fragilidades teóricas e metodológicas dessa produção, contribuindo, dessa maneira, para ultrapassá-las.

As quatro autoras denotam uma preocupação com as fragilidades teóricas e metodológicas da CI. Embora suas pesquisas caracterizem-se por diferentes opções metodológicas, considera-se que tanto os estudos teóricos e empíricos como os metodológicos e avaliativos são fundamentais para que se reconheça na CI um núcleo teórico e prático consolidado e que seus métodos e técnicas sejam transpostos a outros domínios para enriquecerem as possibilidades de análises de produção científica em diferentes áreas, em uma relação dialógica de contribuição com tais domínios, corroborando a interdisciplinaridade característica da CI.

\section{Tipos de autorias no corpus de análise}

Em relação aos tipos de autoria identificados no corpus de 26 artigos assinados por 43 autores, nota-se que os estudos sobre o tema surgem a partir de 1978, somente em autoria individual, o que presume trabalhos advindos de reflexões resultantes de amadurecimento dos pesquisadores em relação à prática do fazer pesquisa. A década de 1980 também foi marcada pela incidência dos estudos de autoria única. Somente no ano de 2000, aparece um estudo em dupla autoria, representando, ainda, a metade do número das pesquisas de autoria única que eram realizadas na referida década. Já, em 2006, aparece o primeiro trabalho em autoria tripla.

Os trabalhos em autoria única perduraram até 2008. Há somente dois estudos com cinco autores, respectivamente em 2007 e 2009. A autoria quádrupla inicia em 2007 e tem seu ápice em 2010. Por fim, no último ano analisado (2012), somente se observa autoria quádrupla sobre a temática.

Em relação ao tipo de autoria das pesquisadoras em destaque, observa-se que Gomes, González de Gómez, e Silva apresentam autoria única em ambos os trabalhos que produziram, ao passo que Bufrem realiza um dos estudos em coautoria com Santos para aprofundar-se na presença do método etnográfico na literatura em CI e o outro estudo para validar o protótipo da Base Brapci, em coautoria com mais três pesquisadores. Este último, considerado um estudo metodológico como fim, faz parte de uma tipologia de pesquisa não muito incidente na área e que apresenta maior complexidade para sua realização e conclusão.

\section{Análise de citação dos autores mais representativos do corpus de análise}

Frohmann foi um dos autores citados por $\mathrm{Bu}$ frem e por González de Gómez, com incidência expressiva de cinco citações, em especial para a última autora. Este autor apresenta uma visão direcionada ao aspecto social da CI, quando faz crítica à dimensão cognitiva da área, considerando os aspectos epistemológicos e metodológicos que favorecem o enfrentamento dos desafios identificados no campo. Pode-se dizer que essa abordagem da epistemologia política possibilita o estudo das complexas relações entre atores envolvidos no processo informacional.

Nota-se que Frohmann é voltado ao domínio da Filosofia da Ciência, enquanto Castells, também citado por Bufrem e González de Gómez, é oriundo da Sociologia. Já a autora mais citada por Gomes é Oliveira, que também faz menções a Castells em seu referencial.

González de Gómez cita autores que trouxeram contribuições expressivas ao desenvolvimento da CI em relação à conceituação da informação científica, destacando Mikhailov, Chernyi e Gilyareski, cada um com duas incidências. 
Figura - Autores citados e acoplados pelas autoras mais representativas na temática

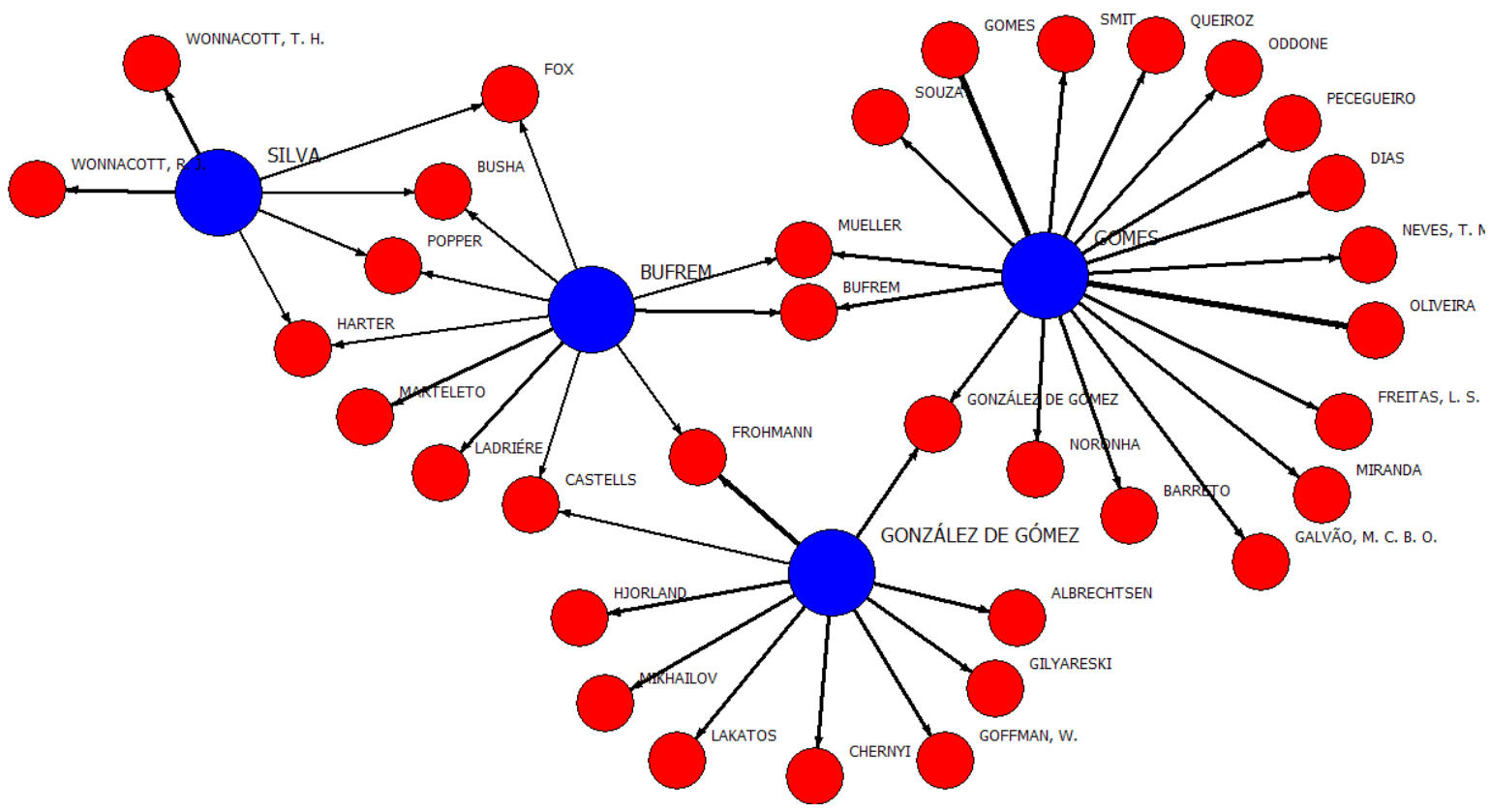

Fonte: os autores, 2014

Além destes últimos mencionados, outros autores da área de CI seriam Hjørland e Albrechetsen, também citados por González de Gómez (2000) em relação à análise de domínio, cuja dimensão social é enfatizada no que tange ao contexto e suas especificidades. Estes autores explicitam sua proposta na obra Toward a new horizon in information science: domain-analysis. As abordagens pelas quais pode ser realizado esse tipo de análise em um contexto específico foram objeto de posterior publicação somente por Hjørland em 2002.

Goffman, citado por González de Gómez (2000), foi o pioneiro da Ciência da Informação matemática. A autora o cita, especialmente em relação aos estudos de recuperação da informação (RI). Segundo González de Gómez (1999-2000), a RI por meio de máquinas, a formalização de linguagens para os sistemas de informação e também os estudos bibliométricos buscariam "fundamentar generalizações e teorias na leitura de regularidades empíricas e em sua formalização nomológica, tal como nas leis de Bradford e nas teorias epidemiológicas da 'disseminação de ideias' de William Goffman” (GONZÁLEZ DE GÓMEZ, 1999-2000).

Wonnacott e Wonnacott foram citados por Gilda Olinto do Valle Silva, devido às pesquisas estatísticas por eles realizadas. A autora referencia as obras "Introdução à Estatística" (1980) e "Fundamentos da Estatística" (1985), embora não tenham sido encontradas citações destes autores no corpo do texto.

Karl Popper foi citado por Silva (1990), pela obra "Conjeturas e refutações" e por Bufrem e Santos (2009b), pela obra "A lógica da pesquisa científica”. O autor, citado pelas pesquisadoras, notabiliza-se por suas obras na área de Filosofia da Ciência.

Considerando que o empirismo reduz todo conteúdo do conhecimento às determinações observáveis, as leis e teorias científicas são hipotéticas e conjeturais, ou seja, na concepção de Popper, uma teoria confirmada é uma teoria que ainda não foi infirmada, isso é, as verdades existem, mas têm prazo de validade. O importante, argumenta o autor, é compreender "como as teorias se verificam", já que o irracional é elemento de toda e qualquer descoberta. Assim, "o que caracteriza o método científico é justamente o desejo de expor deliberadamente as teorias, de todos os modos possíveis, ao crivo da refutação, e não o de procurar defendê-las ou preservá-las sistematicamente" (POPPER, 1975, p. 110-113).

Como racionalismo crítico, a epistemologia de Karl Popper baseia-se nos seus três mundos: 
mundo físico, mundo mente/consciência e mundo das ideias/registros intelectuais. A partir das dimensões ideológicas de Popper, desenvolveu-se a Teoria Cognitiva da Recuperação da Informação (RI), alicerçada especialmente nos estudos de Belkin e Ingwersen (1992 apud ALMEIDA et al., 2007, p. 21).

O britânico Bertram Brookes (1980) também se baseou na epistemologia de Popper. Conforme Prado (2013), Brookes fundamentou-se "na aplicação da lei cunhada por Popper e sua abordagem focou as perspectivas contidas na parte que descreve os aspectos do "mundo 3", constituído pelos produtos intelectuais". Brookes justifica seu raciocínio em defesa da dimensão da informação como coisa, exatamente com as relações desta natureza com os princípios de Popper (PRADO, 2013, p. 4).

Busha e Harter (1980), citados por Silva (1987), Bufrem e Santos (2009b), são coautores da obra Research methods in librarianship. Pode-se dizer que a produção destes autores contribui com a área aproximando-se da posição epistemológica de Popper, em relação ao desenvolvimento da dimensão cognitiva na CI, relativa a usuários e à busca pela informação.

Gomes cita de modo expressivo as pesquisas de Oliveira. Embora esta última não tenha sido citada pelas outras três autoras mais produtivas, apresenta um referencial relacionado à temática interdisciplinaridade da CI e caminhos da pesquisa na área.

Em uma de suas pesquisas, Oliveira (1999) analisa as características das dissertações produzidas no curso de mestrado em Ciência da Informação da Universidade Federal da Paraíba (UFPB). Como contribuição às categorizações temáticas, faz uma comparação de seus resultados com estudo similar realizado por Järvelin e Vakkari, autores também citados por Bufrem (2009a). Segundo esta autora (1996), o levantamento de Järvelin e Vakkari parece ter estabelecido o sistema mais consistente de categorias, pois seus estudos têm sido utilizados como base para muitos que o seguiram. Järvelin e Vakkari (1993, p. 129) con- firmam, por meio de análise de conteúdo, que nas últimas décadas a literatura em Biblioteconomia e CI apresentou muitas análises estatísticas sobre as pesquisas publicadas. Entretanto, segundo os autores, nenhum dos mais recentes estudos cobre todo o leque de opções temáticas e metodológicas.

Mueller é citada por Gomes (2006) e Bufrem e colaboradores (2010), entretanto as autoras se referem a obras distintas. Gomes menciona obras de Mueller produzidas em colaboração da autora com outros pesquisadores, a saber: "O periódico Ciência da Informação na década de 1990: um retrato da área refletido em seus artigos", em coautoria com Pecegueiro (2001) e "A pesquisa em Ciência da Informação no Brasil - análise dos trabalhos apresentados no IV Enancib" na década de 2000, em coautoria com Miranda e Suaiden. Por sua vez, Bufrem e seus colaboradores citam a pesquisa de Mueller intitulada "A comunicação científica e o movimento de acesso livre ao conhecimento" (2006).

Em relação à autocitação, ou referência que um autor faz em seu próprio artigo a trabalhos por ele publicados, é uma prática usual e até recomendada, sempre com a devida cautela, quando a produção sobre o tema é incipiente, como é o caso deste estudo. Além disso, observa-se que são importantes para a construção da pesquisa no sentido de que as autoras apresentam uma produção amadurecida sobre a temática, não somente refletida no corpus analisado, mas também em outras pesquisas identificadas no Curriculum Lattes das autoras. Assim, encontram-se cinco incidências de autocitação nos estudos de Gomes, três nos de Bufrem e duas nos de González de Gómez. Gomes cita as duas autoras que a precederam, González de Gómez e Bufrem, em duas oportunidades.

Corrobora-se o já mencionado na introdução deste estudo, ou seja, a literatura na área abarca uma diversidade temática com pequena incidência de estudos relacionados aos modos de fazer pesquisa. Dessa constatação, pode-se aferir que a reflexão epistemológica e metodológica é incipiente na $\mathrm{CI}$, o que coincide com a crítica de 
Hjørland quando afirma que poucos pesquisadores têm analisado os pressupostos filosóficos por trás de diferentes abordagens em Ciência da Informação (2000, p. 524). Segundo o autor, a compreensão mais profunda de uma área de pesquisa é fornecida pelo estudo de pressupostos filosóficos subjacentes a ela, que representam o aspecto mais negligenciado pelos pesquisadores (HJØRLAND, 2000, p. 527). Tal afirmação vai ao encontro da necessidade de se fazer pesquisa sobre a pesquisa para desenvolver a prática e a teoria de uma área, simultaneamente, sem ignorar suas bases filosóficas.

\section{Considerações finais}

É importante salientar que a seleção do corpus de análise abrangeu somente as pesquisas que contemplavam o termo metodologia e suas variações conforme a descrição dos procedimentos metodológicos. Embora o termo epistemologia também pudesse recuperar estudos relativos a fundamentos metodológicos da pesquisa na área, a opção eleita justifica-se devido à necessidade de delimitação do corpus e aprofundamento no tema.

Observou-se que os tipos de pesquisa predominantes realizados pelas autoras mais produtivas foram: a pesquisa descritiva com enfoque teórico e a pesquisa metodológica como fim.

Essa constatação recai sobre a questão do amadurecimento no fazer científico, demandado para possibilitar a reflexão sobre o próprio método e o processo de investigação.

Também se observa que as autoras unanimemente refutam a visão tecnicista relativa aos modos de fazer pesquisa, em que a metodologia da pesquisa científica é considerada um livro de normas prescritivas, conforme alerta Mills (1972, p. 132), insistindo na recusa a qualquer esquema rígido de procedimentos, por parte do "artesão intelectual".

A visão social da CI e a preocupação epistemológica é outro fator abrangido pela análise de cita- ção realizada, com destaque especial a González de Gómez, fundamentada mais especificamente na epistemologia política. Dentre os autores citados que priorizam o enfoque social, Hjørland ganha evidência. A epistemologia racionalista crítica de Karl Popper com sua dimensão cognitiva como aspecto focal na construção do conhecimento e da pesquisa também foi apresentada de modo expressivo nas análises, embora o core de autores tenha sido pouco numeroso por razões já manifestas.

\section{Referências}

ALMEIDA, D. P. R. et al. Paradigmas contemporâneos da Ciência da Informação: a recuperação da informação como ponto focal. Revista Eletrônica Informação e Cognição, v. 6, n. 1, p. 16-27, 2007. Disponível em: <http://www2.marilia.unesp.br/revistas/index.php/ reic/article/viewFile/745/647>. Acesso em: 30 jun. 2014.

BRUYNE, P.; HERMAN, J.; SCHOUTHEETE, $M$. Dinâmica da pesquisa em Ciências Sociais: os polos da prática metodológica. Rio de Janeiro: Francisco Alves, 1977.

BUFREM, L. S. Configurações da pesquisa em Ciência da Informação. DataGramaZero: Revista de Ciência da Informação, v. 14, n. 6, dez. 2013. Disponível em: <http://www.dgz.org.br/dez13/Art_04.htm>. Acesso em: 30 jun. 2014.

BUFREM, L. S. Linhas e tendências metodológicas na produção acadêmica do Mestrado em Ciência da Informação do Instituto Brasileiro de Informação em Ciência e Tecnologia - Universidade Federal do Rio de Janeiro (1972-1995). 1996. Tese (Concurso para Professor Titular Métodos e Técnicas de Pesquisa) - Setor de Ciências Humanas, Letras e Artes, Universidade Federal do Paraná, Curitiba, 1996.

BUFREM, L. S. Práticas de organização e divulgação da produção intelectual em Ciência da Informação no Brasil. Encontros Bibli: Revista eletrônica de Biblioteconomia e Ciência da Informação, n. esp., p. 36-53, 1º sem. 2008. Disponível em: <https:// periodicos.ufsc.br/index.php/eb/article/view/1518 2924.2008v13nesp1p36/1591>. Acesso em: 30 jun. 2014.

BUFREM, L. S. Opções metodológicas em pesquisa: a contribuição da área da Ciência da Informação para a produção de saberes no ensino superior. Proposta de pesquisa para a obtenção da Bolsa de 
Produtividade em Pesquisa do Conselho Nacional de Desenvolvimento Científico e Tecnológico (CNPq), 2009a.

BUFREM, L. S.; COSTA, F.D. de O.; GABRIEL JR., R.F.; PINTO, J.S. de P. Modelizando práticas para a socialização de informações: a construção de saberes no ensino superior. Perspectivas em Ciência da Informação, v. 15, n. 2, p. 22-41, maio/ago. 2010. Disponível em: <http://www.scielo.br/scielo. php?pid=S1413-99362010000200003\&script $=$ sci arttext>. Acesso em: 30 jun. 2014.

BUFREM, L. S.; SANTOS, S. F. Ciência da informação e uso metodológico da etnografia. ETD: Educação Temática Digital, v. 11, n. 1, p. 148-174, dez. 2009b. Disponível em: <http://www.fae.unicamp.br/revista/ index.php/etd/article/view/1997/pdf_106>. Acesso em 30 jun. 2014.

CHALMERS, A. F. ¿Qué es esa cosa llamada Ciencia? una valorización de la naturaleza y el estatuto de la ciencia y sus métodos. México: Siglo Veintiuno, 2000.

FREITAS, J. L.; BUFREM, L. S. O ensino da metodologia científica: repercussões na produção científica em Ciência da Informação. In: CETAC.MEDIA e Universidad de León. (Org.). Globalização, Ciência, Informação. 1. ed. Porto: Faculdade de Letras da Universidade do Porto - CETAC.MEDIA, 2013. p. 446-460.

GLÄNZEL, W. Bibliometrics as a research field: a course on theory and application of bibliometric indicators. 2003. Disponível em:

$<$ http://citeseerx.ist.psu.edu/viewdoc/ download?doi=10.1.1.97.5311\&rep=rep1\&type=pdf $>$. Acesso em: 9 jan. 2011

GOMES, H. F. A transferência de informação na educação universitária: implicações do uso da oralidade, da escrita e outras tecnologias: metodologia e instrumentos. Informação \& Sociedade: Estudos, v. 9, n. 2, p. 273-290, 1999. Disponível em: <http://www.ies. ufpb.br/ojs/index.php/ies/article/download/386/307>. Acesso em: 30 jun. 2014.

GOMES, M. Y. F. F. Dissertações defendidas no Programa de Pós-Graduação em Ciência da Informação da UFMG, na década de 1990: um balanço. Perspectivas em Ciência da Informação, v. 11, n. 3, p. 318-334, set./dez. 2006. Disponível em: <http://www.scielo.br/scielo.php?script=sci arttext\&pid=S1413-99362006000300003 $>$. Acesso em: 30 jun. 2014.
GONZÁLEZ DE GÓMEZ, M. N. Metodologia da pesquisa no campo da Ciência da Informação. Revista de Biblioteconomia de Brasília, v. 23-24, n. 3, p. 333346, 1999-2000.

GONZÁLEZ DE GÓMEZ, M. N. Metodologia de pesquisa no campo da Ciência da Informação. DataGramaZero: Revista de Ciência da Informação, v. 1, n. 6, 2000. Disponível em: <http://www.dgz.org.br/ dez00/Art_03.htm>. Acesso em: 30 jun. 2014

GRÁCIO, M. C. C.; OLIVEIRA, E. F. T. Indicadores de citação. 2013. Anotações de aula. Universidade Estadual Paulista Júlio de Mesquita Filho, Marília-SP, 2013a.

GRÁCIO, M. C. C.; OLIVEIRA, E. F. T. Análise de cocitação de autores: um estudo teórico-metodológico dos indicadores de proximidade, aplicados ao GT7 da ANCIB. Liinc em Revista, v. 9, n. 1, p. 196-213, maio 2013b. Disponível em: <http://revista.ibict.br/liinc/ index.php/liinc/article/view/527/401>. Acesso em: 30 jun. 2014.

GUEDES, V.; BORSCHIVER, S. Bibliometria: uma ferramenta estatística para a gestão da informação e do conhecimento, em sistemas de informação, de comunicação e de avaliação científica e tecnológica. In: CINFORM - ENCONTRO NACIONAL DE CIÊNCIA DA INFORMAÇÃO, 6., 2005, Salvador. Anais... Salvador: ICI/UFBA, 2005. Disponível em: $<$ http://www.feg.unesp.br/ fmarins/seminarios/ Material\%20de\%20Leitura/Bibliometria/ Artigo\%20Bibliometria\%20-\%20Ferramenta\%20 estat\%EDstica\%20VaniaLSGuedes.pdf>. Acesso em: 30 jun. 2014.

HJØRLAND, B. Library and information science: practice, theory, and philosophical basis. Information Processing and Management, v. 36, p. 501-531, 2000.

HJØRLAND, B. Domain analysis in information science: eleven approaches-traditional as well as innovative. Journal of Documentation, v. 58, n. 4, 422-462, 2002.

JAPIASSU, H. Introdução ao pensamento epistemológico. 7. ed. Rio de Janeiro: F. Alves, 1992.

JÄRVELIN, K.; VAKKARI, P. Content analysis of research articles in Library and Information Science. LISR, v. 12, p. 395-421, 1990.

JÄRVELIN, K.; VAKKARI, P. The evolution of Library and Information Science 1965-1985: a content analysis of journal articles. Information Processing \& Management, v. 29, n. 1, p. 129-144, 1993. 
LLOYD, C. As estruturas da história. Rio de Janeiro: Zahar, 1995.

LUCAS, E. O.; GARCIA ZORITA, J. C. Produção científica sobre capital social: estudo por acoplamento bibliográfico. In: ENCONTRO BRASILEIRO DE BIBLIOMETRIA E CIENTOMETRIA, 4., 2014, Recife. Anais... Recife: UFPE, 2014. v. 4. p. 1-8.

MEADOWS, A. J. A comunicação científica. Trad. Antonio Agenor Briquet de Lemos. Brasília: Briquet de lemos, 1999.

MILLS, C. W. A imaginação sociológica. 3. ed. Rio de Janeiro: Zahar Editores, 1972.

OLIVEIRA, M. Características das dissertações produzidas no Curso de Mestrado em Ciência da Informação da UFPB. Informação \& Sociedade: Estudos, v. 9, n. 2, p. 465-488, 1999. Disponível em: <http://www.ies.ufpb.br/ojs/index.php/ies/article/ view/405/326>. Acesso em: 30 jun. 2014.

PRADO, M. A. R. A Fenomenologia da Informação: reflexões essenciais sobre a matriz do conhecimento. DataGramaZero: Revista de Ciência da Informação, v. 14, n. 4, ago. 2013. Disponível em: <http://www.dgz. org.br/ago13/Art_01.htm>. Acesso em: 30 jun. 2014.

RENDON-ROJAS, M. Á. La ciencia de la información en el contexto de las ciencias sociales y humanas: ontología, epistemología, metodología e interdisciplina. DataGramaZero: Revista de Ciência da Informação, v. 9, n. 4, ago. 2008. Disponível em: $<$ http://www.dgz.org.br/ago08/Art_06.htm>. Acesso em: 30 jun. 2014

SÁNCHEZ-GAMBOA, S. Tendências epistemológicas: dos tecnicismos e outros "ismos" aos paradigmas científicos. In: SANTOS FILHO, J. C.; SÁNCHEZGAMBOA, S. Pesquisa educacional: quantidadequalidade. São Paulo: Cortez, 1997.

SILVA, G. O. V. A matriz de dados e a metodologia da pesquisa em Ciência da Informação. Ciência da Informação, v. 16, n. 2, p. 151-155, jul./dez. 1987. Disponível em: <http://revista.ibict.br/ cienciadainformacao/index.php/ciinf/article/ viewFile/1469/1513>. Acesso em: 30 jun. 2014.

SILVA, G. O. V. Metodologia de pesquisa: trabalhando o conceito de uso de biblioteca. Ciência da Informação, v. 19, n. 2, p. 163-167, jul./dez. 1990. Disponível em: $<$ http://revista.ibict.br/ciinf/index.php/ciinf/article/ view/1394/1529>. Acesso em: 30 jun. 2014.

VANZ, S. A.; S. CAREGNATO, S. E. Estudos de citação: uma ferramenta para entender a comunicação científica. Em Questão: Revista da Faculdade de Biblioteconomia e Comunicação, v. 9, n. 2, p. 295-307, jul./dez. 2003. Disponível em: <http://seer.ufrgs.br/ index.php/EmQuestao/article/view/75/35>. Acesso em: 30 jun. 2014.

Research about conducting research: a citation analysis on information science literature

\section{Abstract}

Introduction: This paper considers that information science (IS) literature covers a diversity of thematics with low emphasis on researches about conducting research. The study analyzes the scientific production of authors who investigate about research methodology in the information science (IS) literature, and the references used to lay the foundation of the methodological issues regarding the area. It discusses the methodological and epistemological positions of the leading researchers highlighted as the most productive investigators on the subject in the country. Method: The research adopts the content analysis coupled with metric studies to contextualize the indicators related to productivity, to the types of authorship and citation analysis. The bibliographic coupling method is considered an analysis mode which analyzes concomitant citations. It develops a theoretical framework about the importance of scientific production analysis in different knowledge fields. The study investigates, from a theoretical perspective, the concepts about research methodology and the complementarity between methodology and epistemology in conducting research. Results: The results of the analysis showed that the production of the highlighted authors presents the methodology as a thematic focus to be applied to IS contexts, as well as a research object in the field. The prominent productivity of the authors is justified especially by deepening the meta studies about the ways to conduct research in IS. This study also identifies a trend to singleauthored studies about the theme. Conclusions: The research considers that meta studies and applied and methodological studies are important to recognize a consistent theoretical and practical core in the IS area. Regarding the epistemological influences identified by the citation analysis, the study observes that the critical rationalist epistemology and the social and political epistemology are highlighted in the construction of the theoretical framework of the most productive authors.

\section{Keywords}

Information Science. Scientific production analysis. Citation analysis. Bibliographic coupling. Research methodology.

\section{Agradecimentos:}

Trabalho apoiado por concessão de bolsa da Fundação de Amparo à Pesquisa do Estado de São Paulo (Fapesp).

Recebido em 30 maio 2014

Aceito em 1 julho 2014 
Sobre os autores:

\section{Juliana Lazzarotto Freitas}

Bacharel em Gestão da Informação - UFPR, Especialista em Gestão de Negócios - UFPR, Mestre em Ciência, Gestão e Tecnologia da Informação - UFPR, Doutoranda em Ciência da Informação - Unesp, Bolsista da Fundação de Amparo à Pesquisa do Estado de São Paulo - Fapesp.

julilazzarotto@gmail.com

\section{Leilah Santiago Bufrem}

Graduada e licenciada em Filosofia - PUCPR, Graduada em Biblioteconomia e Documentação - UFPR, Mestre em Educação - UFPR, Doutora em Ciências da Comunicação - USP. Professora Visitante Sênior no Programa de PósGraduação em Ciência da Informação - UFPE, Docente do Programa de Pós-Graduação em Ciência da Informação - Unesp, Docente do Programa de Pós-Graduação em Educação - UFPR.

santiagobufrem@gmail.com

\section{Ely Francina Tannuri de Oliveira}

Graduada em Pedagogia - Unesp, Graduada em Matemática - Faculdade de Filosofia Ciências e Letras Osvaldo Cruz, Mestre e Doutora em Educação - Unesp, Docente do Programa de Pós-Graduação em Ciência da Informação Unesp/Marília, Livre-Docente do Departamento de Ciência da Informação - Unesp/Marilia.

etannuri@gmail.com

\section{Maria Cláudia Cabrini Grácio}

Bacharel em Estatística - Unicamp, Mestre em Estatística - Unicamp, Doutora em Filosofia - Unicamp, Docente do Programa de Pós-Graduação em Ciência da Informação Unesp/Marilia.

cabrini@marilia.unesp.br

\section{Como citar este artigo:}

FREITAS, J. L.; BUFREM, L. S.; OLIVEIRA, E. F. T. de; GRÁCIO, M. C. C. A pesquisa sobre o fazer pesquisa: uma análise de citação da literatura periódica em Ciência da Informação. AtoZ: novas práticas em informação e conhecimento, Curitiba, v. 3, n. 1, p. 38-49, jan./jun. 2014. Disponível em: <http://www.atoz.ufpr.br>. Acesso em: 